\title{
Author Response to manuscript: "Religious Behavior, Sleep Quantity, Sleep Quality, and Sleep Disorders in American Adults"
}

\author{
Sat Bir Khalsa, PhD
}

This letter states, "Khalsa and others have reported benefits of spiritual practices in the management of poor sleep quality reported benefits of spiritual practices in the management of poor sleep quality," and cites our study as a citation for this statement. Our study did no more than acquire a few anecdotal reports from some students that sleep was improved with yoga practice. I do not believe our paper can be used as a justifying citation for this author's statement. There are other citations that are much more appropriate supporting the contention for yoga-mediated improvements in sleep. ${ }^{1-4}$

Furthermore, it is a little misleading to indicate that we "reported benefits of spiritual practices" in reference to our yoga intervention study, especially in the context of the authors' subsequent discussion devoted to religious practices. Yoga is a non-religious, mind-body practice, although yoga practice may have some effect on spirituality.

Sincerely,

Sat Bir Khalsa

\section{References}

1. Kudesia RS, Bianchi MT. Decreased nocturnal awakenings in young adults performing bikram yoga: a low-constraint home sleep monitoring study. ISRN Neurology 2012.

2. Vera FM, Manzaneque JM, Maldonado EF, et al. Subjective Sleep Quality and hormonal modulation in long-term yoga practitioners. Biological Psychology, 2009; 81(3):164-8.

3. Chen KM, Chen MH, Chao HC, et al. Sleep quality, depression state, and health status of older adults after silver yoga exercises: cluster randomized trial. International Journal of Nursing Studies, 2009; 46(2):154-63.

4. Khalsa SB. Treatment of chronic insomnia with yoga: a preliminary study with sleep-wake diaries. Applied Psychophysiology and Biofeedback, 2004;29(4):269-78.

Address correspondence to Sat Bir Khalsa, PhD, Department of Medicine, Brigham and Women's Hospital, 221 Longwood Avenue, Boston, MA 02115, USA. Phone: +1-617-7327994; Email: khalsa@hms.harvard.edu.

Journal of Behavioral Health Services \& Research, 2013. 135. (c) 2012 National Council for Community Behavioral Healthcare. DOI 10.1007/s11414-012-9310-2 